\title{
A INFLUÊNCIA DA FILOSOFIA DO DIREITO DE HEGEL NO CONCEITO DE SOCIEDADE EM LIMA VAZ
}

\author{
Maria Celeste de Sousa ${ }^{1}$
}

\section{Resumo:}

Este artigo discorre sobre o diálogo entre Lima Vaz e Hegel na organização da sociedade de direito. Lima Vaz adere ao aspecto formal e teleológico do sistema hegeliano e pensa o movimento da ideia de sociedade nos três planos lógicos: o plano político, o plano democrático e o plano ético expressando, assim, a relação entre Ética e Direito. Seu objetivo é retomar os conceitos clássicos de Bem (Agathón), de Justiça (dike) e de Direito (dikaion) que são os fundamentos da vida democrática, forma ética do político e que garante a Dignidade Humana. Ele está dividido em três tópicos: 1) A forma universal de sociedade: a relação política; 2) A forma particular de sociedade: a relação democrática; 3) A forma singular de sociedade: a relação ética.

Palavras chaves: Sociedade, Bem, Justiça, Direito, Dignidade Humana.

\section{Résumé:}

Cet article parle du dialogue entre Lima Vaz et Hegel dans l'organisation de la société de droit. Lima Vaz s'associe à l'aspect formel et logique hégélienne système téléologique et croit que le mouvement, l'idée de la société en trois plans logiques: le plan politique, le plan démocratique et le plan de l'éthique, donc exprimer la relation entre l'éthique et le droit. Votre objectif est de retourner les concepts classiques de Bien (Agathon), la Justice (digue) et droit (dikaion) que sont les fondements de la vie démocratique, à l'éthique politique et qui assure la dignité de l'homme. Il est divisé en trois thèmes : 1) La forme universelle de la société : la relation politique; 2) la forme particulière de la société : la relation démocratique; 3) La forme singulière de la société: la relation éthique.

Mots-clés: La société, le Bien, la Justice, le Droit, la Dignité de l'homme.

\section{Introdução}

Este artigo objetiva mostrar como a filosofia do Direito de Hegel influencia diretamente o conceito de sociedade em Lima Vaz. Esta influência refere-se ao aspecto formal e teleológico do sistema hegeliano (cf. SAMPAIO, 2006, p. 237). Pelo aspecto formal Lima Vaz adere metodologicamente à estrutura triádica de universalidade,

\footnotetext{
${ }^{1}$ Doutora em Filosofia pela PUC-SP. Coordenadora do Curso de Filosofia da Faculdade Católica de Fortaleza. Vice-coordenadora do GT Um Olhar Interdisciplinar sobre a Subjetividade Humana (UECE). Professora colaboradora do Mestrado Acadêmico (UECE). Professora de Filosofia na Faculdade Católica de Fortaleza e da Rede Pública de Ensino do Estado do Ceará.
} 
particularidade e singularidade. O momento da universalidade visa a totalidade em-si imediata $^{2}$ do conceito de sociedade expresso pela relação política. A particularidade é a mediação conceptual entre a universalidade e a singularidade e refere-se à relação democrática ou relação do direito, negação do puramente universal e determinação do conceito de sociedade no limite do ser particular. A singularidade é a reflexão do particular em-si mesmo como concreto e verdadeiro ${ }^{3}$ expresso pela relação ética. $\mathrm{O}$ aspecto teleológico ${ }^{4}$ refere-se ao movimento dialético, passagem da universalidade abstrata à particularidade e retorno ao universal na concretude da singularidade do conceito de sociedade.

O movimento da ideia de sociedade em Lima Vaz processa-se, então, por meio dos três planos lógicos constitutivos: o plano político, o plano democrático e o plano ético expressando a relação entre Ética e Direito nas relações intersubjetivas. Por meio desse movimento dialético ele retoma os conceitos que justificam a vida segundo o Bem (agathón), ou a Ideia clássica de Comunidade ética, independente das suas modalidades históricas.

O movimento dialético parte da inteligibilidade universal do político. A Política visa estabelecer o exercício do Direito universal dos sujeitos partícipes da mesma comunidade pelo estabelecimento da Lei justa. Discorre-se, portanto, sobre o conceito de Justiça (dike), em seu aspecto subjetivo (Virtude) e objetivo (Lei) e em seguida falase sobre a norma universal do Direito (dikaion). Demonstra-se, em seguida, a forma particular do conceito de sociedade por meio da reflexão sobre o conceito vaziano de situação. Esse conceito expressa a suprassunsão dialética da universalidade da Justiça e do Direito por meio da prática intersubjetiva das diversas virtudes que correspondem às diferentes circunstâncias da vida comunitária. Posteriormente, enfatiza-se a Ideia de Democracia, forma ética que possibilita o exercício da participação livre na sociedade de direito.

Discorre-se, por fim, sobre a forma singular do conceito de sociedade por meio da reflexão sobre o conceito de Dignidade humana, que é a forma concreta do

\footnotetext{
2 "Ela é conceito enquanto pressuposição da racionalidade primeira e constitutiva do real, ou ainda enquanto resulta, em termos hegelianos, da supressão dialética da oposição entre ser e essência". (SAMPAIO, 2006, p. 238).

3 "A singularidade, na lógica hegeliana, visa à terceira das determinações do conceito. Ela apresenta a identidade reflexiva da universalidade primeira e da particularidade na qual se exprime inicialmente sua riqueza." (Ibid.. p. 329).

4 "Ele caracteriza-se por um movimento que é, ao mesmo tempo, progressão (linha) e retorno (círculo), cumulativo e progressivo. $\mathrm{O}$ aspecto teleológico se faz presente em cada uma das obras de Lima Vaz, em todo o seu sistema, e em todo o seu itinerário filosófico.” (Ibid., p. 242-243.)
} 
reconhecimento universal da pessoa que encontra o sentido de sua existência na convivência comunitária e estabelece a igualdade pelo reconhecimento recíproco da dignidade dos iguais dentro da Comunidade ética.

\title{
A forma universal de sociedade: a relação política
}

No plano da universalidade da relação política Lima Vaz reflete sobre as categorias de Justiça e Direito. A Ideia da Justiça (dike) circunscreve-se no âmbito da reflexão filosófica grega, que pela primeira vez na história ocidental interpretou o ethos à luz da Razão demonstrativa (lógos apodeitikós) e estabeleceu como fundamentos da vida ética, a Ideia do Bem (tó agathón) e a ideia do Justo (dikaion):

\begin{abstract}
Ora, o Bem e o Justo, na sua transcendência ideal, apresentam-se imediatamente com um caráter deontológico. O Bem conhecido é princípio de obrigação interior, e o Justo, ao ser pensado, mostra-se imediatamente como o melhor, sendo, portanto fonte da excelência própria da virtude (eudaimonia), que é o fim de toda prática ética. (VAZ, 1996, p. 30).
\end{abstract}

É a partir dessa herança grega que Lima Vaz pensa a Justiça como a categoria que inicia o movimento dialético da vida ética, e, por meio dela, resgata a interligação entre os conceitos normativos fundamentais da práxis intersubjetiva que são: a Ética, a Política e o Direito.

Conforme essa intuição clássica de politeia e de acordo com o pensamento antropológico aristotélico-tomista que vê o homem como um vivente político (zôon politikón), exatamente porque ele é um vivente racional (zôon logikón), Lima Vaz reflete sobre a dialética da Justiça com o intuito em demonstrar a racionalidade que vincula o agir ético à norma universal da Justiça na sociedade.

Seu pensamento visa "legitimar o poder pela justiça na perspectiva de uma teleologia do Bem e fazer da vontade política uma vontade instauradora de leis justas uma nomotética regida pela razão do melhor" (VAZ, 1993, p. 259), o que implica a interligação entre as duas faces da Justiça: a Virtude (areté) e a Lei (nómos). Para Aristóteles, a Justiça (dike) é, com efeito, a "disposição de caráter que torna as pessoas propensas a fazer o que é justo, que as faz agir justamente e desejar o que é justo" (ARISTÓTELES, 1987, p. 81).

A interligação do aspecto subjetivo da Justiça como areté e o aspecto objetivo como nómos constitui, para Lima Vaz, um invariante conceptual que permanece ao 
"longo do tempo assegurando a identidade do conceito na diferença com que se apresenta nas suas distintas versões históricas" (VAZ, 2000, p. 177-178.)

Lima Vaz explica a categoria da Virtude (areté $^{5}$ como a dinâmica existencial entre a posse permanente do Bem pelos sujeitos éticos, o que lhes configura sua identidade ética, e, ao mesmo tempo, como o direcionamento da sua intencionalidade para o horizonte universal, que é o fim da sua práxis virtuosa:

Trata-se de uma categoria que se constitui por uma dialética entre o estático ou o já possuído (a virtude como qualidade do sujeito bom) e o dinâmico ou ainda não alcançado (a virtude como movimento do sujeito bom para um crescimento contínuo no Bem) (VAZ, 1993, p. 148).

O agir ético expressa-se, em consequência, como um agir necessariamente virtuoso, um ato racional em vista do melhor, ou do bem individual e comunitário. A proporção entre o Bem e a razão comunitária é exatamente o Justo, a distribuição equitativa do bem comum: "o justo como mediador entre o Bem e seus beneficiários passa a ser então a forma do ethos na sua transposição aos códigos da Razão" (VAZ, 1996, p. 31). Em sua expressão objetiva, o Justo manifesta-se na forma institucional mais elevada, a sociedade política, e na sua expressão subjetiva, a forma de hábito virtuoso.

A expressão subjetiva do Justo refere-se à prática da Virtude como habitus $^{6}$ individual que visa o bem comum e que necessariamente direciona-se para o outro, visa o direito do outro, porque ela manifesta o ato intencional em prol da igualdade ${ }^{7}$ na comunidade. A prática virtuosa da justiça retifica, evidentemente, as ações intersubjetivas e torna os homens bons uns para com os outros.

O Justo objetivo que estabelece, por outro lado, a ordem e a partilha equitativa do Bem na comunidade é o Direito que estabelece e legitima a Lei comum. Logo, a Justiça como Lei "é uma regulação permanente do agir dos indivíduos tendo em vista o bem da comunidade" (VAZ, 2000, p.178) e, como tal, ela é a justiça legal (nómimon díkaion) que obriga os sujeitos a obedecer a Lei em prol do bem comum e que implica a denominação de Justo somente ao sujeito que respeita a lei comum.

\footnotetext{
5 "Podemos mesmo descobrir nesses dois termos a presença do gênio grego e do gênio romano em sua concepção dessa forma superior do agir que é o agir segundo a virtude. Para o grego na areté esplende a idéia (eidos) do Bem realizado (face estática da virtude); para o romano manifesta-se na virtus a força (dýnamis) de realização do Bem (face dinâmica da virtude)" (VAZ, 2000, p.149).

6 "A justiça é o habitus, pelo qual, com vontade constante e perpétua, se dá a cada um o seu direito." (TOMAS DE AQUINO, 2005, p. 56)

7 "O nome da justiça implica igualdade, por isso, em seu conceito mesmo, a justiça comporta relação com outrem. Pois, nada é igual a si mesmo, mas a um outro". (Ibid., 2005, p. 58).
}

\begin{tabular}{|l|l|l|l|l|}
\hline Qepista Dialectus & Ano 2 & n. 3 & Julho-Dezembro 2013 & p. 57-69 \\
\hline
\end{tabular}


Para Lima Vaz, a intuição clássica do "par conceptual Virtude-Lei” constitui um invariante inteligível e essencial da categoria da Justiça e manifesta a praticidade da Virtude dentro da comunidade e a efetivação histórica da Justiça como ordenação da práxis intersubjetiva:

É formalmente na relação com o outro no espaço simbólico da vida-emcomum que a virtude, ou a excelência do agir individual, se faz justiça, vem a ser excelência do agir na relação com o outro ou agir comunitário (VAZ, 2000, p. 178).

Ademais, como a Justiça visa imediatamente o bem comum, ela pode ser considerada uma virtude completa, como afirma Aristóteles na Ética a Nicômaco ${ }^{8}$, no sentido que possibilita o exercício atual da virtude no sujeito para consigo mesmo e, ao mesmo tempo, para com o outro; e, por abranger todas as formas da existência comunitária, ela é considerada a maior das virtudes. ${ }^{9}$

A prática da Justiça evidencia, com efeito, a relação constitutiva da Intersubjetividade como uma relação entre a Virtude e a Lei, e é justamente este par conceptual Virtude-Lei que fundamenta a vida ética:

O existir-em-comum não é mais do que a efetivação concreta da vida ética individual. Portanto, se a justiça é a forma universal do existir-em-comum, sendo assim a forma primeira da vida ética na comunidade, é necessário concluir que uma relação essencial une, em sua distinção, as duas manifestações com que a justiça se apresenta, seja como virtude, seja como lei. (VAZ, 2000, p. 180).

O princípio que unifica essa relação essencial entre a Virtude e a Lei é o Bem (agathón), princípio que possibilita a vida comunitária segundo o exercício do Direito. ${ }^{10}$ Lima Vaz, semelhante a Hegel resgata, evidentemente, a unidade clássica entre a Ética e o Direito e reafirma a articulação entre a práxis (agir) e o bem (fim). e posiciona-se a favor da organização social pautada na Lei (nómos) da "justa medida", que assegure a convivência comunitária pelo exercício da igualdade (isonomia) e da equidade (eunomía).

A Política é, nesse sentido, a ciência normativa da práxis comunitária que estabelece as regras e os critérios racionais do consenso cívico em torno do mais justo e

\footnotetext{
8 'Somente a justiça, entre todas as virtudes, é o 'bem de um outro' (Platão, Rep. 343), visto que se relaciona com o nosso próximo, fazendo o que é vantajoso a um outro, seja um governante, seja um associado". ( ARISTÓTELES, 1987, p. 82).

9 "Por isso a justiça é muitas vezes considerada a maior das virtudes, e 'nem Vésper, nem a estrelad'dalva' são tão admiráveis; e provavelmente 'na justiça estão compreendidas todas as virtudes' (Teógnis, 147). (Ibid., p. 82).

10 "Direito é o que está conforme à regra ou à lei (droit, diritto, derecho, rigth, das Recht). Em grego dikaion é o que está de acordo com a díke, e em latim justus o que é medido pelo jus. Essa etimologia nos põe na pista da significação clássica do Direito". (VAZ, 2000, p.119).
}

\begin{tabular}{|c|c|c|c|c|}
\hline Revista Qialectus & Ano 2 & n. 3 & Julho-Dezembro 2013 & p. $57-69$ \\
\hline
\end{tabular}


ordena a vida na polis. A Política é, enfim, “a outra face da Ética”. (VAZ, 1993, p. 136) e deverá justificar a razão imanente ao consenso intersubjetivo por meio do Direito.

Ora, sendo o horizonte do político referente à ordenação do bem comum, a racionalidade do Direito circunscreve-se no campo da práxis da autorrealização do sujeito, que é capaz de dar razão ao seu existir comunitário como um cidadão (politês) e, consequentemente, capaz de explicitar a passagem do social empírico para o social político, no qual ele vivencia a sua "segunda natureza", como um sujeito de direitos e deveres:

Ao ser reconhecido na sua existência política, ou seja, como membro da comunidade política, como cidadão (polítês), o homem se constitui, portanto, sujeito de direitos ou sujeito universal. (VAZ, 1993, p. 140).

A prática individual e social da Justiça na vida comunitária está, contudo, continuamente ameaçada pelo seu contrário, a prática da injustiça que nega incondicionalmente as propriedades essenciais da vida justa que são a equidade e a igualdade. A presença da injustiça no âmbito da Justiça aponta para o indivíduo que “deve viver essa dimensão da vida ética” (VAZ, 1993, p. 184) na comunidade, em meio à multiplicidade condicional em que a injustiça pode efetivar-se.

O movimento lógico-dialético do conceito de sociedade direciona-se, então, para a situação particular em que os sujeitos continuamente são desafiados a praticar a justiça, pelo exercício livre do reconhecimento e do consenso, por meio da "forma mais alta de organização política", a relação democrática.

\section{A forma particular de sociedade: a relação democrática}

A reflexão sobre a Democracia, no momento da particularidade do movimento lógico sobre a expressão ética da sociedade, tenta demonstrar a interligação que Lima Vaz faz entre a Ética e Direito na práxis virtuosa do cidadão (politês). A práxis virtuosa reconhece, com efeito, o direito comum dos cidadãos e livremente participa na luta pelo consenso social em prol do exercício desse direito. Lima Vaz vê a Democracia como "a forma mais alta de organização política a que pode aspirar uma sociedade" (VAZ, 1993, p. 263). porque ela delimita um espaço de significação axiológica, pelo encontro entre a atitude livre do cidadão (politês) e o exercício da justiça (dike) em prol do bem comum. Ele está convicto de que a "superioridade da forma democrática da vida política só é pensável a partir da essência ética do político”. (VAZ, 1993, p. 265). 
Essa essência ética do político também é uma herança grega deixada à civilização ocidental, na aurora da prática democrática, e expressa a forma como os gregos compreendiam a realização da liberdade dos cidadãos na vida comunitária. Para os gregos, com efeito, "a ação política se definia como a forma mais elevada do agir ético" (VAZ, 1988, p. 12). Situado no âmbito do problema da soberania, ou da relação entre o indivíduo e o poder, a reflexão política grega versa sobre a melhor politéia ou sobre a organização social mais justa.

Dessa sorte, para Lima Vaz, o problema real da politiké epistéme aristotélica não é a relação entre o indivíduo e o poder, mas a "relação entre as virtudes do cidadão e a ordem da comunidade. Elas não pretendem ser uma ciência política na acepção moderna, mas uma Ética política” (VAZ, 1988, p. 12), uma práxis conforme o exercício da Lei (nómos).

A Democracia nascente expressa assim, a "vitória da liberdade" pela intrínseca relação que fez entre o ético e o político, pois se a política tem como finalidade a vida justa e feliz, isto é, a vida propriamente humana digna de seres livres, então ela é inseparável da ética e é somente a partir dessa relação que a Democracia se apresenta como a melhor forma de organização social e política:

\footnotetext{
A democracia - como ideal e como prática - aprofunda necessariamente a essência ética do político ao definir em termos de liberdade participativa e responsável a resposta do cidadão à regulação da Lei definindo o corpo político na sua expressão simbólica fundamental como eklesía dos eleútheroi - assembléia dos homens livres - que têm direito de participar, de falar e de decidir. (VAZ, 1993, 265).
}

A ideia de Democracia constitui uma "idéia reguladora e normativa" que efetiva na sociedade a "essência ética do político". Com efeito, a práxis democrática concretizando o fim da Justiça pelo exercício do Direito e, por ele, a regra consensualmente estabelecida e promulgada da Lei, efetiva o reconhecimento da legitimidade do bem comum ou a igualdade entre iguais. Lima Vaz empreende, em consequência, "a tarefa de pensar os desdobramentos históricos da Ideia de Democracia fundada no problemático conceito de igualdade política”. (PERINE, 2002, p. 320) presente nos estados modernos.

O modelo democrático moderno, sedimentado na ideologia individualista estabelece historicamente a separação entre o ético e o político e modifica radicalmente o sentido do conceito de igualdade (isonomia), que era compreendida pelos filósofos clássicos como uma propriedade da Justiça (dike). Para a filosofia política clássica era, com efeito, inconcebível a ética fora da koinonia ou da comunidade dos iguais. Ora, a 
teoria moderna ao separar a Ética da Política perde o qualificativo da práxis intersubjetiva como virtus, como práxis direcionada para o bem individual e comunitário, e enfatiza a igualdade entre os sujeitos em parâmetros quantitativos ou matemáticos:

O pressuposto mecanicista deste tipo de pensamento reduz assim os indivíduos a grandezas iguais, a átomos movendo-se num espaço social isotrópico. Tal modelo repousa sobre a hipótese da igualdade natural entre os homens da qual resultaria a constituição da sociedade pelo pacto de associação entre iguais. (VAZ, 1985, p. 267).

Ora, é exatamente esse conceito de igualdade natural defendido na Modernidade pela teoria do direito natural, que pressupõe a existência de indivíduos independentes e isolados, que decidem voluntariamente tornarem-se sócios em uma sociedade a fim de garantir os seus interesses particulares, que se torna problemático na democracia moderna, porque segundo Lima Vaz, a natureza não é o domínio da igualdade, mas o domínio da diferença de cada um, o que impossibilita a experiência intersubjetiva do reconhecimento do outro como outro eu e do consentimento livre em conviver com ele na sociedade: "a única igualdade possível aqui é aquela que resulta da negação da diferença qualitativa; a igualdade abstrata do número”. (VAZ, 1985, p. 267).

Ao erigir essa igualdade abstrata como modelo de sociabilidade, os estados modernos individualizam os sujeitos e criam um sistema mecânico de associação social pautado na força exterior da Lei. Contudo, esse modelo de organização social traz consigo a possibilidade real da prática totalitária, pois no momento em que a Lei concentrar-se na mão de um só, ou de uns poucos, como a história já mostrou, o sistema totalitário se instalará como forma de organização social, em que "todos são iguais porque todos são escravos" (VAZ, 1985, p. 268).

Diante dessa tensão existente entre o exercício do poder e a sociedade, nos Estados modernos, a reflexão sobre a Ideia de democracia requer, segundo Lima Vaz, a clareza sobre o conceito de igualdade. Então, primeiramente, ele critica a noção de que a "igualdade é constitutiva da ideia de democracia" (VAZ, 1985, 267). A igualdade social, embora seja um pressuposto necessário, não manifesta suficientemente a essência da relação democrática porque situa-se no primeiro momento lógico-dialético da estrutura conceptual do universo político.

Ora, a racionalidade própria desse momento lógico-dialético do "social" é justamente a racionalidade da igualdade em relação à natureza e à interdependência social em prol da satisfação das necessidades materiais e econômicas. A igualdade 
preconizada entre os sujeitos na sociedade é, em consequência, uma igualdade natural, e devido à expansão dessa racionalidade a todos os âmbitos das relações intersubjetivas, nas sociedades modernas, o grande desafio que essas sociedades enfrentam atualmente é o trânsito deste modelo de igualdade "social" para o modelo da igualdade "política".

Ora, a igualdade "política" situa-se em outro nível de racionalidade, isto é, a racionalidade expressa pela relação de intersubjetividade em que, por meio do reconhecimento do outro, enquanto outro eu, a relação recíproca se apresenta como uma igualdade na diferença de cada um:

Ela se caracteriza pela suprassunção da igualdade abstrata, própria do primeiro nível, no qual as diferenças naturais dos indivíduos são equalizadas abstratamente na sua universal dependência da natureza e na sua universal interdependência nos vínculos do sistema econômico, na igualdade concreta, aquela na qual as diferenças naturais e adquiridas (culturais) são equalizadas na isonomia ou na igualdade perante a lei. (VAZ, 1988, p. 19).

Trata-se, portanto, de uma igualdade que não elimina a diferença na relação abstratamente homogênea da dominação, mas a suprassume na relação concretamente diferenciada do reconhecimento como afirmou Hegel na Fenomenologia do Espírito. Esta é a dialética do político iniciada pelos gregos e que Lima Vaz resgata também, por meio do conceito de reconhecimento. Ela fundamenta a essencial sociabilidade humana como uma forma superior de convivência social, que eleva a igualdade da particularidade individual à universalidade de ser reconhecida no seio da Comunidade ética.

A sociedade política ou o Estado de direito representa uma forma superior de Comunidade ética na história das sociedades humanas, porque supera o poder despótico da tyrannía e exerce o poder pautado em leis (nómos basileus). Todavia, Lima Vaz infere também uma sutil diferença entre o Estado de direito e o Estado democrático:

Todo Estado democrático é um Estado de direito, mas nem todo Estado de direito é um Estado democrático. Há uma mudança na matriz conceptual, pois a ideia geratriz não é mais a ideia de justiça, mas a ideia de liberdade participante. (VAZ, 1988, p. 19).

Logo, na vigência do Estado democrático, a experiência de igualdade ultrapassa o nível do ato justo, para o nível do ato livre que se efetiva concretamente pela participação dos cidadãos nas discussões e decisões em torno do bem comunitário.

Na sociedade democrática, a dialética da igualdade na diferença desdobra-se, por conseguinte, em um nível mais profundo de convivência social, que é exatamente, a dimensão da liberdade pessoal. Nela, a igualdade alcança o nível do ético, porque a participação na assembleia dos "homens livres" exige uma prática virtuosa. A prática 
democrática da deliberação e da escolha livre expressa, assim, a "vitória da liberdade" sobre o poder despótico e a intrínseca relação entre o ético e o político.

O Filósofo brasileiro especifica a diferença entre a práxis política e a práxis democrática enfatizando o problema central de cada uma. O problema da sociedade política é a "justiça nas leis", pelo exercício da melhor constituição e o problema da sociedade democrática é a "justiça na alma", pelo exercício da consciência moral do sujeito nesse sentido, a Democracia não é somente um regime político determinado, mas uma "ideia reguladora e normativa" que orienta o exercício da liberdade. Lima Vaz afirma que a Democracia não é uma ideia utópica, mas um difícil e contínuo aprendizado da liberdade. A sociedade democrática expressa, enfim, "a forma superior de comunidade política porque se constitui formalmente como essa resposta da consciência moral de cada cidadão ao apelo da sua consciência política”. (VAZ, 1985, p. 272).

O movimento lógico-dialético do político culminou no projeto democrático de sociedade, como expressão da liberdade pessoal e comunitária. Nesse espaço político, Lima Vaz infere a experiência concreta "da essencial dignidade do homem, que reside no seu ser moral" (VAZ, 1988, p. 22). A tentativa na efetivação de uma Democracia real requer, primeiramente, o plano das exigências éticas para a práxis política:

É nesse plano que irá decidir-se, afinal, o êxito da experiência democrática e, com ele, o próprio destino do homem político, como ser dotado de uma essencial dignidade. (VAZ, 1988, p. 22)

Concluindo a demonstração da essência ética do político, como uma prática democrática, Lima Vaz avança a reflexão para o terceiro momento da Ideia de sociedade, que é a comunidade ética, em que enfatiza o segundo enfoque do problema da Ideia de Democracia consistindo em "recuperar no plano ético a noção de dignidade humana e articulá-la com a ideia de democracia, essa igualmente reformulada na perspectiva de uma unidade orgânica entre Ética e Política”. (PERINE, 2002, p. 318).

\section{A singularidade da sociedade: a relação ética}

No plano da singularidade do conceito de sociedade, Lima Vaz reflete sobre os níveis graduais de efetivação da Dignidade humana na esfera políticossocial. O primeiro nível refere-se à vida social ou econômica em que a vida digna requer a satisfação das necessidades básicas dos cidadãos elencadas na Declaração dos Direitos Humanos. O 
segundo nível relaciona-se ao plano político e requer a dignidade cívica que exige a igualdade perante a lei e a reciprocidade entre direitos e deveres na sociedade e, por fim, no nível democrático, a dignidade se expressa pela participação livre do cidadão na vida política como compromisso ético.

Somente o exercício prático desses três níveis graduais da Dignidade humana poderá favorecer o reconhecimento da dignidade pessoal e conferir à relação intersubjetiva o qualificativo de comunidade ética. Lima Vaz dissolve, portanto, o aparente paradoxo da alteridade, pois o indivíduo torna-se cada vez mais consciente de seu eu, exatamente no encontro com o outro. O reconhecimento recíproco da dignidade pessoal de cada membro na comunidade efetiva concretamente o universal da Justiça (dike) em seu aspecto subjetivo, como Virtude (areté), e em seu aspecto objetivo, como Lei (nómos).

Lima Vaz apresenta um encadeamento dialético entre o Eu e o Nós na prática da Justiça. Ele afirma: "Eu sou para o Bem (sujeito ético = dignidade individual) $\rightarrow$ Nós somos para o Bem (comunidade ética = dignidade comunitária)" (VAZ, 2000, p. 203). A Dignidade humana tem a sua origem e o seu fundamento, por conseguinte, no estatuto metafísico do indivíduo e da comunidade decorrente da sua ordenação transcendental ao Bem. Nesse sentido, a ideia de Dignidade humana não pode ser fruto de um costume ou de uma convenção socialmente constituída, mas tende para a "unicidade do ser humano no seu ser-para-si e no seu ser-para-o-outro. É, portanto, indissoluvelmente um predicado no indivíduo e uma qualidade essencial do vínculo que une os indivíduos na comunidade" (VAZ, 2000, p. 203).

O que se infere nesta reflexão vaziana sobre a Dignidade humana é que a sua concepção de igualdade social difere da concepção de igualdade defendida pelas teorias modernas do contrato social. Lima Vaz não concebe a igualdade como um número presente na carteira de identidade que operacionaliza a relação indivíduo e Estado, nem somente como uma igualdade proporcional na participação dos bens socialmente produzidos, mas como uma igualdade que é "fruto do reconhecimento recíproco da dignidade dos iguais" cuja natureza se apresenta como uma tarefa a cada indivíduo, de ser cada vez mais livre para a prática do bem e de comprometer-se com os ditames da sua consciência moral em prol do bem comum.

A vida ética na comunidade demonstra, por fim, a singularidade das formas universais do reconhecimento e do consenso social, que nada mais são do que a forma 
como a razão prática se desdobra na relação intersubjetiva como instituição política, democrática e ética.

\section{Conclusão}

O conceito hegeliano de Direito abrangendo o Direito abstrato, moralidade e eticidade subjaz ao pensamento vaziano de sociedade, à medida em que o Filósofo brasileiro expõe pelo movimento dialético os invariantes conceptuais da vida ética. A ideia de sociedade organiza, com efeito, as determinações essenciais que qualificam a vida-em-comum efetivando pela práxis política, a ideia do Direito (dikaion) entre os sujeitos partícipes da mesma comunidade, pelo estabelecimento da Lei justa. Essa ideia universal da Justiça e do Direito suprassume-se na situação por meio da práxis intersubjetiva das virtudes de prudência, fortaleza e temperança que correspondem às diferentes circunstâncias da vida comunitária e efetiva o regime ético e político da Democracia. O exercício democrático possibilita, enfim, o reconhecimento da Dignidade humana como forma concreta do reconhecimento universal da pessoa, que encontra o sentido de sua existência na convivência comunitária efetivando a igualdade, pelo reconhecimento recíproco da dignidade dos iguais dentro da Comunidade ética.

\section{Referências}

LIMA VAZ, H. C. de. Escritos de Filosofia II: ética e cultura. São Paulo: Loyola, 1993. 2000 .

Escritos de Filosofia V: introdução à ética filosófica II. São Paulo: Loyola,

Democracia e dignidade humana. In: Síntese Nova Fase, Belo Horizonte, CES: Loyola, v. 15, n. 44, pp. 11-25, 1988.

O ser humano no universo e a dignidade da vida. In: Cadernos de Bioética, Belo Horizonte, n. 2, pp. 27-41, 1993.

Democracia e sociedade. In: Síntese Nova Fase, v. 11, n. 32, pp. 5-19, 1985.

Ética e Justiça: filosofia do agir humano. In: Síntese Nova Fase, v. 23, n. 75, pp. 437-454, 1996.

\begin{tabular}{|l|l|l|l|l|}
\hline Qevista Dialectus & Ano 2 & n. 3 & Julho-Dezembro 2013 & p. 57-69
\end{tabular}


ARISTÓTELES. Ética a Nicômaco. Tradução de Leonel Vallandro e Gerd Bornheim da versão inglesa de W. D. Ross. São Paulo: Nova Cultural, 1987.

PERINE, Marcelo. Democracia e filosofia do agir humano: observações sobre uma luminosidade do conceito de justiça. In: MAC DOWELL J. A. (Org.). Saber filosófico, história e transcendência. São Paulo: Edições Loyola, 2002.

SAMPAIO, Rubens Godoy. Metafísica e Modernidade. São Paulo: Edições Loyola, 2006.

TOMÁS DE AQUINO. Suma Teológica: v. VI, II seção da II parte - questões 57 122. São Paulo: Edições Loyola, 2005. 